\title{
25 Research Soure \\ Genetic Diversity of Toxigenic Fusarium \\ Verticillioidesassociated with Maize Grains in India
}

\section{Vishwambar Navale}

CSIR-National Chemical Laboratory: National Chemical Laboratory CSIR

KoteswaraRao Vankudoth ( $\nabla$ v.koteswara@ncl.res.in )

National Chemical Laboratory CSIR https://orcid.org/0000-0002-3131-0015

\section{Research Article}

Keywords: Fusarium verticillioides, diversity, mycotoxin, pathogenicity, maize, food safety

Posted Date: October 26th, 2021

DOI: https://doi.org/10.21203/rs.3.rs-1003824/v1

License: (c) (1) This work is licensed under a Creative Commons Attribution 4.0 International License. Read Full License 


\section{Abstract}

Genetic diversity of Fusarium species associated with maize grains were analyzed from ten states of India. Fusarium verticillioides (88.52\%), F. coffeatum (6.55\%), F. foetens (3.27\%) and F. euwallaceae $(1.63 \%)$ were recovered from the maize samples. A phylogenetic analysis was performed based on the translation elongation factor 1 alpha (TEF1- $a$ ) gene sequence formed five evolutionary lineages (EL) that showed both inter- and intra-species variability. A In-vitro pathogenicity study confirms that among the 61 strains, $51 \%$ exhibited high to moderate virulence to the maize, and produced one or more mycotoxins. The genetic diversity of $F$. verticillioides were evaluated using Inter simple sequence repeats (ISSR) fingerprints. The ISSR fingerprints (AG)8C and (AG)8G shown 252 and 368 microsatellites sites, respectively, in the genome of $F$. verticillioides. The (AG)8C fingerprints differentiated the pathogenic and non-pathogenic clustering of $F$. verticillioides. However, Simpson's (SID), and Shannon's (H) index showed a wide range of diversity within the $F$. verticillioides. The pleomorphic nature of these strains role in host pathogen interactions and adoptive potential to develop disease to crop plants. Toxigenic potential of $F$. verticillioides was evaluated for the presence of FUM1and FUM13 genes involved in fumonisins B1 (FB1) biosynthesis, and further confirmed by liquid chromatography with tandem mass spectrometry (LC$\mathrm{MS} / \mathrm{MS}$ ) showed $91 \%$ strains were FB1 producers. The current finding demonstrated that most $F$. vertcillioides strains showed a wide range of genetic diversity with varied toxigenic and pathogenic potentials. Thus, there is an urgent need to develop an effective resistant breeding program in maize, and further monitoring is necessary for the post-harvest losses of grains.

\section{Introduction}

Maize (Zea mays L.) is a widely distributed cereal crop after wheat and rice [1, 2]. It is used for various purposes such as livestock feed (45\%), human food (11\%), and industries (44\%) [3]. It has a high nutritional value, starch (60-68\%), proteins (7-15\%), fat (5-6\%), vitamins (Pantothenic acid, folate, vitamin B6, and niacin), and minerals (manganese, phosphorus, magnesium, zinc, and copper). It also has antioxidant activity that protects the cell's DNA from damage and improves digestion [4]. Food and agriculture organization (FAO) predicted that by 2030 the overall demand for maize will increase to around 300 million tons [5]. Fusarium is a ubiquitous plant pathogenic fungus that endanger plant growth and consistently adulterate economically important agriculture produce [6, 7]. F. graminearum, $F$. culmorum, F. avenaceum, F. poae, F. sporotrichioides, F. equiseti, F. verticillioides, and F. proliferatum are the predominant species that infect maize, rice, wheat etc., and cause vascular wilt, head blight, root rot, stem canker and plant death [8-10]. F. verticillioides is a dominant species, thus affecting the yield, nutritional value, and quality of the grains $[11,12]$. Fusarium species contaminate stored grains, fruits, cereals, nuts and produce numerous mycotoxins [13-15]. Fumonisins (FUM), Zearalenone (ZEA), Trichothecenes (TRI) produced by Fusarium species, known to cause acute to chronic toxicity in humans and animals $[16,17]$. The exposure of humans and animals to mycotoxin defiled food could result in teratogenicity, estrogenic effects, carcinogenesis, immune suppression, and neurotoxicity [18]. 
FB1 is an inhibitor of ceramidase synthase and an important enzyme in sphingolipid biosynthesis. Upon consumption of FB1 contaminated food leads to detrimental effect to the humans and animals. It is hepatotoxic, nephrotoxic, and carcinogenic and causes esophageal cancer [19], neural tube defects (NTD), and congenital cerebral defects [20]. In addition, the intake of toxins infected food grains by humans and animals could result in low nutrient absorption, retarded growth in infants, malnutrition, immunosuppression, and also affects the gut microbiota.

Fusarium is a diverse fungal genus with over 300 species [21]. The species identification is a challenging task for mycologists and food microbiologists due to closely related species and more than 20 species complexes. The barcoding of the internal transcribed spacer (ITS), translational elongation factor $1 \mathrm{a}$ (TEF-1 a), RNA polymerase II subunit (RPB2), and $\beta$-tubulin (Bt2) could assist in classifying them within the species complex $[22,23]$. TEF1- $\alpha$ is one of the most preferred molecular marker for the sub sections of Fusarium species [23]. Furthermore, microsatellite inter simple sequence repeats (ISSR) is an important marker to study the genetic diversity for identifying the highly polymorphic multilocus markers [24]. Microsatellite fingerprint differentiates closely related species complexity, genetic diversity, genome mapping, and evolutionary lineages $[25,11]$.

Icial (SID) index alpha (TeThe food and feed matrices contaminated with multi mycotoxins, which can be identified using multiplex PCR assays for simultaneous detection in a single analysis[26]. The FUM1 and FUM13 genes involved in the FB1 biosynthesis were located within a $42.5 \mathrm{~kb}$ region in $F$. verticillioides genome [27, 28]. The European Commission has set tolerable limits for FUM is $2000-4000 \mu \mathrm{g} / \mathrm{kg}$ in raw cereals and grains [29]. However, there is a lack of well-regulated efforts for resolving such issues in India $[30,31]$. Hence, the present study aimed to assess the genetic diversity of $F$. verticillioides using ISSR fingerprints. Furthermore, FB1 producing $F$. verticillioides were evaluated by PCR and liquid chromatography-mass spectrometry (LC-MS/MS) to ensure the grain quality for the safety of the consumers.

\section{Materials And Methods Primer designing}

Primers were designed for the molecular detection of mycotoxins by targeting their biosynthetic pathway genes such as FUM1 and FUM13 involved in biosynthesis of FB1 using SnapGeneViewer and analyzed with the help of PRIMER-BLAST and BLASTN tools to eliminate, if any non-specific targets in the PCR assay.

\section{Sampling, isolation and identification of Fusarium species}

A total of 140 stored maize grain samples were collected from the poultry industries of ten states, Maharashtra (MH), Rajasthan (RJ), Madhya Pradesh (MP), Andhra Pradesh (AP), Uttar Pradesh (UP), Bihar (BH), Tamilnadu (TN), Karnataka (KA), Jharkhand (JK), and Uttarakhand (UK), India. The collected 
maize samples were analyzed for contamination of Fusarium species on modified Spezieller Nahrstoffarmer agar (SNA) medium [32]. The traditional identification of species of Fusarium was analyzed based on standard manuals and protocols [33].

\section{Molecular identification of Fusarium species}

\section{Genomic DNA/RNA isolation}

The genomic DNA/RNA was extracted from Fusarium species after they achieved optimum growth at 72 h. About $100 \mathrm{mg}$ of mycelia were ground to powder in liquid nitrogen using mortar and pestle. According to the manufacturer's instructions, the genomic DNA/RNA was extracted using DNeasy/RNeasy Plant Mini Kit (Qiagen, Germany). The concentration and purity of extracted DNA/RNA were determined using a Nanodrop Spectrophotometer (Thermo Scientific, USA) and stored at $-20^{\circ} \mathrm{C}$. For reverse transcriptase PCR, total RNA was transcribed using a high-capacity reverse transcription kit (Thermo Fisher Scientific, USA) and an oligo-dT primer. The first-strand cDNA product was used in the PCR with the TEF1-a gene [34]. Further, the species specificity was confirmed with PCR assay using species-specific primer set Vert 1, and Vert 2 primer set specific to $F$. verticillioides (Supplementary Table 1). The PCR was performed in Applied Biosystem veriti (Thermo Fisher Scientific, USA) with a reaction volume of $20 \mu \mathrm{L}$. The amplification mixture consisted of $1 \mu \mathrm{L}$ of each forward and reversed primers (10 $\mu \mathrm{mol} \mathrm{L}-1), 1 \mu \mathrm{L}$ template, $10 \mu \mathrm{LTaq}$ master mix (Jumpstart, Sigma Aldrich), and $8 \mu \mathrm{L}$ MilliQ water. The PCR program was set as an initial denaturation at $95^{\circ} \mathrm{C}$ for 3 minutes, followed by 35 cycles of $95^{\circ} \mathrm{C}$ for $30 \mathrm{~s}, 52^{\circ} \mathrm{C}$ for $30 \mathrm{~s}$, and $72^{\circ} \mathrm{C}$ for $1 \mathrm{~min}$, with a final extension at $72^{\circ} \mathrm{C}$ for 10 minutes. After successful amplification, the PCR product was purified and sequencing was performed as reported previously [35].

\section{Molecular detection of FB1gene by PCR assay}

The molecular detection of FB1 was carried out by targeting biosynthetic pathway genes such as FUM1 and FUM13 respective to FB1 production. The PCR was carried out in a $20 \mu \mathrm{L}$ reaction mixture containing $50 \mathrm{ng}$ template, $10 \mu \mathrm{LTaq}$ master mix, $8 \mu \mathrm{LMilliQ}$ water, $1 \mu \mathrm{L}$ primers $\left(2 \mu \mathrm{mol} \mathrm{L}^{-1} 1\right)$ for each gene. The PCR cycling was set as an initial denaturation at $94^{\circ} \mathrm{C}$ for 4 min, followed by 35 cycles at $94^{\circ} \mathrm{C}$ for $30 \mathrm{sec}$, annealing at $52^{\circ} \mathrm{C}$ for $30 \mathrm{sec}$ and extension at $72^{\circ} \mathrm{C}$ for 1 min with a final extension of $72^{\circ} \mathrm{C}$ for $10 \mathrm{~min}$. The PCR products were loaded onto $10 \mathrm{~g} \mathrm{~L}^{-1}$ agarose gel electrophoresis and visualized under the gel documentation system.

\section{Pathogenicity of Fusarium species}

The effect of Fusarium species on the seed germination, growth, and development of maize was determined using Water-agar (WA) method [36]. Maize seeds were surface sterilized with $0.01 \% \mathrm{HgCl}_{2}$ 
and soaked in $1 \times 10^{6}$ spores $/ \mathrm{mL}$ for $12 \mathrm{~h}$ on an orbital shaker; the seeds were soaked in sterile MilliQ water without spore suspension was used as control. Following incubation, seeds were transferred into plant tissue culture bottles ( $43 \mathrm{~mm}$ ) containing water agar ( $2 \%$ ) under aseptic conditions and incubated for $15 \mathrm{~d}$ at $25^{\circ} \mathrm{C}$ in $16 \mathrm{~h}$ light and $8 \mathrm{~h}$ dark conditions. At the end of the incubation period, root and shoot inhibition was measured. Furthermore, seed germination was evaluated by using 7days grown culture filtrate (CF) of Fusarium species [37]. Further, FB1 extraction of all the strains of Fusarium was carried out using $50 \mathrm{ml} \mathrm{CF}$ of each strain and extracted with equal volume of ACN-MeOH-citrate buffer $(12.5 / 12.5 / 125, \mathrm{v} / \mathrm{v} / \mathrm{v})$ under shaking condition at room temperature for $1 \mathrm{~h}$. The obtained extract was evaporated completely using rotary evaporator (Aditya Scientific, India) and eluted into $200 \mu \mathrm{l}$ MS grade water. The extract was passed through Sep-Pak column (Waters, Ireland), eluted in $50 \mu \mathrm{l}$ of MS grade water containing $0.1 \%$ formic acid and analyzed for the FB1 detection using LC-MS/MS.

\section{Detection of FB1by LC-MS}

An acquity UPLC system (Waters, USA) was used to perform reverse-phase chromatographic partition of the FB1. Peptide BEH C18 column was used for separation with dimensions $2.1 \mathrm{~mm} \times 150 \mathrm{~mm}, 1.7 \mu \mathrm{m}$ particle size, and $4 \mu \mathrm{L}$ injection volume. The column temperature was set at $40^{\circ} \mathrm{C}$, and $8^{\circ} \mathrm{C}$ was the temperature of the sample manager. The separation was carried out with formic acid $(0.1 \%)$ and water (A); and formic acid (0.1\%) and acetonitrile (B) as a mobile phase. An initial gradient used was $90 \% \mathrm{~A}$ and $10 \%$ B for 3 min, and then solvent B was increased linearly to $90 \%$ within 10 min and was kept constant for 2 min. Further, solvent B was decreased linearly to $10 \%$ in $3 \mathrm{~min}$. To avoid carryover in the next acquisition, the column was washed between two acquisitions. The flow rate was $0.5 \mathrm{ml} \mathrm{min}^{-1}$. Eluents were acquired in Mass Spectrometer (TSQ Quantum Access Max mass spectrometer-Thermo Scientific) in positive electrospray ionization (ESI) mode. Each sample was acquired in triplicates. In the ESI+ mode, the MS spray voltage was $4.2 \mathrm{kV}$. The capillary temperature was $300^{\circ} \mathrm{C}$ and probe heating temperature $320^{\circ} \mathrm{C}$ with the sheath gas at 45 arbitrary units and the aux gas was 12 arbitrary units.

\section{Genetic diversity of $F$. verticillioides using Inter Simple Sequence Repeat (ISSR)}

The high frequency occurring $F$. verticillioides isolates were further processed to study the genetic diversity using ISSR markers. The primers were selected based on the polymorphic and reproducible banding patterns to characterize all the $F$. verticillioides isolates; the 20 different ISSR primers containing di or tri-nucleotide repeats were used in the present study (supplementary table 1). The PCR was carried out in a reaction volume of $20 \mu \mathrm{L}$. The amplification mixture consisted of $1 \mu \mathrm{L}$ of forward and reverse primer each (10 $\mu \mathrm{mol} \mathrm{L}-1), 10 \mu \mathrm{LTaq}$ master mix (Jumpstart, Sigma Aldrich), $8 \mu \mathrm{L}$ of MilliQ water, and 40 ng DNA. Sterile MilliQ water was used as a negative control for each experiment. The PCR program was set as an initial denaturation at $95^{\circ} \mathrm{C}$ for 5 minutes, followed by 35 cycles of $95^{\circ} \mathrm{C}$ for $30 \mathrm{sec}, 44^{\circ} \mathrm{C}$ for 45 sec, and $72^{\circ} \mathrm{C}$ for $2 \mathrm{~min}$ with a final extension at $72^{\circ} \mathrm{C}$ for $7 \mathrm{~min}$. The PCR amplified products were loaded 
onto $20 \mathrm{~g} \mathrm{~L}^{\mathrm{L}-1}$ agarose gel electrophoresis in $1 \mathrm{X}$ TAE buffer and visualized under a UV trans-illuminator gel documentation system. The ISSR fingerprint data was analyzed based on the presence or absence of a particular allele indicated as 1 and 0 , respectively. However, the pairwise distance among the strains was calculated using Jaccard's coefficient from the binary matrix. The distance matrices were used to cluster the strains by Unweighted Pair Group Method with arithmetic means (UPGMA). Furthermore, to identify the better threshold microsatellite partitions, the Adjusted Rand value was calculated for each UPGMA/Dice dendrograms to compare each possible combination of microsatellite regions.

\section{Data analysis}

Annotation of sequenced TEF1-a gene was performed using BlastN with default parameters against the NR database. The blast hit results were filtered based on Maximum Query Coverage with maximum identity and lowest e-value. Preference was given to $F$. verticillioides TEF1- $\alpha$ in cases where there was an identical hit from other strains. Phylogenetic analysis was performed using ClustalW of the TEF1-a gene sequences from the isolates. Results of Clustal W were used as input to construct various trees to identify non- $F$. verticillioides gene clusters. The outliers were removed from the analysis, and distance-based trees were constructed. Interactive Tree of Life online tool was used to construct and visualize trees with Newick format as input for analysis. For ISSR analysis, the presence or absence of amplicon observed at a particular locus was scored as 1 and 0 correspondingly, and pairwise distance among the strains was calculated. Amplicon data was grouped into a 500bp window and provided input to unsupervised hierarchical clustering using the UPGMA method. The resultant file was used to identify Clades based on the distance score. Clustering and visualization were done using MegaX software. The tree file was used as input to the ITOL (Interactive Tree Of Life) online tool and the metadata (Geographical and Virulence) to perform circular tree visualization of the clades.

\section{Results}

\section{Isolation and molecular identification of Fusarium species}

A total of 61 different Fusarium isolates were recovered from 140 maize grain samples. The isolated colonies were morphologically identified based on the colony characteristics accompanied by microscopic examination of microconidia and macroconidia. Further, molecular identification of Fusarium species was performed usingTEF1-a gene sequences, which resulted a single and specific amplicon at 300 bp (Supplementary data). The TEF1-a gene sequences were subjected to BLAST analysis at NCBI database and analyzed for the species-level identification. The molecular evolutionary lineages and phylogenetic tree was constructed using MEGA software version X. Amongst, $F$. verticillioides (88.52\%) is the most dominating species, followed by F. coffeatum (6.5\%), F. foetens (3.27\%), and F. euwallaceae (1.63\%). Fusarium strains were formed five major clades based on phylogenetic analysis. Clade I, IV and V consist of 15,16 , and 17 strains of $F$. verticillioides. Clade III consists of 4 strains of F. coffeatum, and clade II consists of 9 different species strains (Figure 1). 
Surprisingly, F. coffeatum, F. foetens, and F. euwallaceae were in between the clade II and III suggest the sequence similarity and closeness of these species, or diversity in the species complexes. The TEF1-a gene sequences showed more than $90 \%$ sequence similarity and perfectly aligned into the clades and subclades. Present study revealed that Fusarium species have a wide range of diversity within the same species collected from the single host. Furthermore, F. verticillioides strains were evaluated using species specific primers showed a single amplicon of $400 \mathrm{bp}$ and conformed the species specificity (Figure 2).

\section{Molecular detection and FB1production}

The early detection of mycotoxigenic fungi in food and feed is of paramount importance. All the obtained F. verticilloides strains were processed for detection of FB1 biosynthesis. FUM1 and FUM13 gene specific amplification was observed at 927, and $852 \mathrm{bp}$ (Supplementary data). The most of the isolates shown the presence of both FUM1 and FUM13 genes involved in FB1biosynthesis. Furthermore, all the strains were analyzed and conformed for the FB1 producers using HPLC/LC-MS/MS Surprisingly, $90 \%$ of the strains were able to produce FB1 confirmed by both molecular and analytical methods (Supplementary data).

\section{Pathogenicity assay of Fusarium species}

Evaluation of pathogenicity of Fusarium isolates were carried out using the WA method. The obtained results indicated a negative effect on seed germination, reduction in the root and shoot growth. For each isolate, mean disease severity (MDS) was measured as low (MSD: < 25\%), moderate (MSD: 25-50\%) and high (MDS: > 50\%). F. verticillioides, F. coffeatum, F. foetens, and F. euwallaceae showed diversification in their pathogenicity (Table 1). The results showed that nine isolates as high disease severity, affecting maize growth; twenty-two isolates as moderate disease severity, and twenty six showed low disease severity with 11 and $24 \%$ inhibition of both root and shoot growth, respectively. Interestingly, 4 isolates of Fusarium species did not reveal any disease severity either on seed germination or shoot and root growth inhibition compared to untreated control. The highly pathogenic nine isolates were collected from $\mathrm{MH}, \mathrm{AP}$, $\mathrm{RJ}, \mathrm{JK}$, and MP, and four non-pathogenic isolates were from MP, RJ, and the UK. The rest of the isolates obtained from various states exhibited low to moderate pathogenicity. However, more detailed studies also needed for the confirmation of pathogenicity with other maize genotypes.

\section{ISSR fingerprint}

The genetic diversity of $F$. verticillioides was determined using microsatellite ISSR fingerprints. The polymorphic nature of all $F$. verticillioidies strains were representative of each of the ten states studied in India. Among, the twenty ISSR primers used for this study, two primers (AG)8C and (AG)8G showed99$100 \%$ reproducibility of banding patterns for $F$. verticillioides. The data with other primers were nonreproducible and less polymorphic, were omitted from the study (data not are shown). The primers 
(AG)8C produced 1-14 bands within $300 \mathrm{bp}$ to $6 \mathrm{~kb}$ and (AG)8G displayed 2-10 bands within $350 \mathrm{bp}$ to $3 \mathrm{~kb}$ amplicon (Supplementary data). The dendrograms obtained using Unweighted Pair Group with Arithmetic Mean (UPGMA/Dice) with (AG)8C primer fingerprints formed five major clades (I to $\mathrm{V}$ ) and 10 to 12 sub-clades, whereas (AG)8G primer finger-prints produced six major clades (I to $\mathrm{VI}$ ) and 10 to 11 sub-clades that represents the high diversity among the $F$. verticilliodies strains. The result suggests that there is random distribution of $F$. verticilliodes strains in the geographic regions (Figure 3 ).

Furthermore, the statistical discriminatory power of both primers was tested using Simpson's (SID) and Shannon's $(H)$ indices for measuring diversity by comparing the partitions online tool. SID was used to calculate the discriminatory potential of the various sets of primers from typing systems, and it indicated the probability of the different population data sets. Consequently, the SID index increases the discriminatory capacity of the typing technique. The confidence interval $(\mathrm{Cl})$ can be compared with the original Non-Approximated Confidence Interval (CINA). The SID and $\mathrm{H}$ indices data obtained after analysis were shown in Table 2. At $95 \% \mathrm{Cl}$, SID and entropy $\mathrm{H}$ were resulted equivalent for both the primers.

Furthermore, (AG)8G specifies the microsatellite component better than those with the (AG) $8 \mathrm{C}$ fingerprint. The partition computations for each UPGMA/Dice dendrogram of the microsatellite component have been adjusted from 50 to $95 \%$. The both (AG) $8 G$ and (AG)8C, the maximum coefficient value was determined to be 0.230 at a threshold of $65 \%$ (Fig 4). SID partitions value reported as 0.762 with (AG)8C at this threshold, 13 clusters found with SID values at these cutoffs. Similarly, (AG)8G generated 14 clusters with SID values of 0.785 for the partitions, and there was no significant difference between (AG)8G and (AG)8C, except for BIONCL-20, BIONCL-37, BIONCL-28, BIONCL-29, BIONCL-40, BIONCL-42, BIONCL-43, BIONCL-47, BIONCL-51, and BIONCL-56, which were classified into distinct clades.

The UPGMA dendrograms of (AG)8G fingerprints were more distinct than the (AG)8G examined based on clades and subclades. However, (AG)8G ISSR primer forms six major clades which are distributed nevertheless their geographic origin, but significantly correlated with the disease severity on maize. Clade I consist of more than $75 \%$ strains that showed low disease severity, except four strains originated from $\mathrm{TN}$. The strains were obtained from $\mathrm{MH}$ showed moderate or high disease severity, clade II strains showed only moderate disease severity, whereas clades (III, IV, V) strains showed moderate or high disease severity except BIONCL 4 strain demonstrated low disease severity and three strains showed no disease severity. However, clade VI strains demonstrated low disease severity, except BIONCL 57 showed no disease severity (Figure 5). More comprehensive research, may necessitate for the genetic diversity of F. verticilliodes in maize genotypes.

\section{Discussion}

The worldwide distribution of Fusarium species has rendered with high variability in its evolutionary characteristics. Apart from the fact, there is a lack of continuity in its taxonomy. Interestingly, Fusarium species were classified based on morphological observations revealed more than 1,000 
species, strains, and forms [38]. Moreover, there is an extensive diversity among the unresolved Fusarium within the species [39]. The detailed and reliable classification system is still needed due to its high pathogenicity, and toxicity to plants and humans [40]. Most of the classifications within the species were based on the pathogenic behavior and vegetative compatibility groups (VGC) that aided imprecise identification of TEF1-a gene in diverse Fusarium species [41,42]. A total of 61 isolates were obtained, and 54were belongs to the F. verticillioides [43]. F. verticillioides is a dominating species with a characteristic feature for producing a variety of mycotoxins in different food crops [11]. However, there were no extensive studies conducted on molecular diversity of $F$. verticilliodes in India. Also, these species infect and contaminate different food crops viz., paddy, sorghum, small cereal grains, poultry, and cattle feed during the post-harvest period and produce various mycotoxins. Recently, Deepa et al. [44] reported $74 \%$ of $F$. verticillioides strains were associated with various food samples from Karnataka, India, in which $42 \%$ of strains showed positive signals for FUM production. In addition to its toxicity, F. verticillioides can cause the stalk corn rot in maize cultivars in Assam, India [45] and even resistant maize cultivar [46].

We have isolated, F. coffeatum, F. foetens, and F. euwallaceae in addition to F. verticillioides. $F$. verticillioides have been considered a plant pathogen belonging to FFSC, known to cause head, stalk, and root rots in maize due to the active production of FUM [47]. F. coffeatum belonged to the Fusarium incarnatum-equiseti species complex (FIESC), whereas $F$. foetens is a sister taxon of the Fusarium oxysporum species complex (FOSC) and a well-known plant pathogen that infect various cereals, including maize and ornamental crops [48-50]. F. euwallaceae, a symbiotic fungus of Euwallacea sp., was identified in an invasive ambrosia beetle from Israel and California, belongs to the Fusarium solani species complex (FSSC), showing the distinctive ecologies and exclusive lineage within Clade 3 of the FSSC [51]. To the best of our knowledge, there were no reports available either of the species, F.coffeatum, F. euwallaceae and F. foetens associated with food grain samples from India [52]. In the present study, for the first time, we reported these novel species, isolated from stored maize samples and their ability to produce FB1.

In addition to the precise identification of the species, molecular detection of mycotoxins biosynthetic pathway genes are utmost important for evaluating the toxigenic fungi to ensure the quality of the food. The traditional approaches are labor intensive and time consuming. Hence, the molecular methods have become a robust alternative due to their flexibility, precision, and low time requirements compared to the conventional methods. The developed PCR assay was able to detect FB1 from the culture and maize grains due to the high sensitivity and specificity of the primers [11].

In the present study, 54 isolates of $F$. verticillioides were evaluated for their genetic diversity study using ISSR fingerprints [53]. The ISSR fingerprints recognized the six clades and about $50 \%$ of the diversity within $F$. verticillioides. The microsatellite DNA formed several repetitive motifs that demonstrated substantial distinction among isolates. Moreover, no correlation was observed between the clustering within the $F$. verticillioides respective to geographical regions. Nevertheless, (AG)8G fingerprint formed six major clades, which showed a strong correlation with pathogenicity $[54,55]$. Interestingly, Leyva- 
Madrigal et al. [56] studied the polymorphic nature of ISSR markers, and 470 microsatellites were observed in the genome of $F$. verticillioides. ISSR fingerprints facilitated the studies on the relationships between $F$. verticillioides and showed SID ranged from 0.034 to 0.78 with both the fingerprints. The (AG) $8 \mathrm{C}$ and (AG)8G markers revealed 252 and 368 microsatellites sites, respectively. About $90 \%$ of $F$. verticillioides enabled the produce FB1 which are isolated from the maize [55]. In the recent past, the diversity in Fusarium led to the description of several new specific and infra-specific taxa by examining the large populations. The association mapping using diverse genotypes was a promising and effective approach to gain useful insights that determined the functional variability of both known and unknown genes [57]. On the other hand, Fusarium species were profiled for toxigenic potentials using HPLC/LC-MS. About 31 strains showed moderate to high pathogenicity, on growth of the maize. The FB1 produced by $F$. verticillioides might be a virulence factors in disease development [58]. In addition, these species were known to possess virulent genes, which translated to the pathogenic proteins, thereby causing plant pathogenesis. However, there is a need to prove this hypothesis through mechanistic studies, determining the exact pathogenicity factors [59].

\section{Conclusion}

The molecular characterization of toxigenicity and pathogenicity of $F$. verticillioides strains associated with the stored maize grains from poultry industries in India was studied. F. coffeatum, $F$. euwallaceae and $F$. foetens were the first time reported from maize grain, India which produce FB1.The current observation revealed the polymorphic nature of seed borne $F$. verticilliodes exhibited wide genetic diversity, severe pathogenic to maize studied by ISSR fingerprint. The (AG) ${ }_{8} G$ molecular marker could be efficiently used to precise identification and characterization of pathogenic $F$. verticilliodes populations. Furthermore, the ISSR fingerprint clearly segregate the pathogenic and non-pathogenic clades in the $F$. verticillioides irrespective of the geographical origins. The identified and characterized molecular markers are more imperative for developing a disease-resistant crop breeding programme, which could lead to effective control of Fusarium pathogen. These findings might helps to understand the molecular mechanisms of host pathogen interaction and virulence of the pathogen to propose disease management policies based on molecular markers.

\section{Declarations}

The Author's declares that they don't have no competing Interests

\section{Acknowledgments:}

This work was supported by Science and Engineering Research Board (SERB); Department of Science and Technology, Government of India; and CSIR-National Chemical Laboratory, Pune, India by providing the necessary facilities. 


\section{Consent for publication:}

Not Applicable

\section{Availability of data and materials:}

Not Applicable

\section{Competing Interest:}

The Author's declares that they don't have no competing Interests for the present research study.

\section{Consent to participate:}

Not Applicable

\section{Conflict of interest:}

The authors have declared that no conflict of interest exists.

\section{Ethical statement:}

This article does not contain any studies with human or animal subjects performed by any of the authors.

\section{Declarations:}

This present material is Author's original work, which has not been previously published elsewhere.

\section{Authors' contributions}

Vishwambar persuaded the concept and drafted the manuscript.

Dr.V. Koteswara Rao, conceptualization, scientific correction, and English editing of the manuscript.

\section{Code availability:}

Not Applicable 


\section{References}

1. Foreign Agricultural Service/USDA. Office of global analysis (2019) https://ipad.fas.usda.gov

2. Companhia Nacional de Abastecimento [CONAB] Acompanhamen to da safrabrasileira de grãos, v. 5-Safra 2017/18, 2018; n. 4-Quarto levantamen to, janeiro

3. USDA-ERS Employment in agriculture (2018) Food, and related industries, USDA- Economic Research Service, Washington

4. Bathala S, Jaidka M, Kaur R (2017) Nutritive value. Annual report, IntechOpen. https://doi.org/10. 5772/intechopen.88963

5. Food and Agriculture Organization [FAO]. The future of food and agriculture - Trends and challenges. Rome. 2017

1. Ekwomadu TI, Gopane RE, Mwanza M (2018) Occurrence of filamentous fungi in maize destined for human consumption in South Africa. Food Sci Nutr 6(4):884-90

2. Balendres M, Karlovsky P, Cumagun C (2012) Mycotoxigenic Fungi and Mycotoxins in Agricultural Crop Commodities in the Philippines: A Review. Foods 8(7):249

3. Garmendia G, Pattarino L, Negrín C, Martínez-Silveira A, Pereyra S, Ward TJ, et al (2018) Species composition, toxigenic potential and aggressiveness of Fusarium isolates causing Head Blight of barley in Uruguay. Food Microbiol 76:426-33

4. Pasquali M, Beyer M, Logrieco A, Audenaert K, Balmas V, Basler R, et al (2016) A European Database of F. graminearum and F. culmorum Trichothecene Genotypes. Front Microbiol 7: 406

5. Covarelli L, Stifano S, Beccari G, Raggi L, Lattanzio VMT, Albertini E (2012) Characterization of Fusarium verticillioides strains isolated from maize in Italy: Fumonisin production, pathogenicity and genetic variability. Food Microbiol 31(1):17-24

6. Aiyaz M, Divakara ST, Mudili V, Moore GG, Gupta VK, Yli-Mattila Ti, et al (2016) Molecular Diversity of Seed-borne Fusarium Species Associated with Maize in India. Current Genomics. 17(2):132-44

7. Chehri K (2017) Fusarium Species in Agriculture Industry and Control of Them. Agri Res \& Technol open access $\mathrm{J}$ 6(2)

8. Summerell BA (2019) Resolving Fusarium: Current Status of the Genus. Ann Rev of Phytopathol. 57(1):323-39

9. Minati MH, Mohammed-Ameen MK (2019) Novel report on six Fusarium species associated with head blight and crown rot of wheat in Basra province, Iraq. Bull Natl Res Cent 43, 139. https://doi.org/10.1186/s42269-019-0173-z

10. Askun T (2018) Introductory Chapter: Fusarium: Pathogenicity, Infections, Diseases, Mycotoxins and Management. Fusarium -Plant Diseases, Pathogen Diversity, Genetic Diversity, Resistance and Molecular Markers. https://doi.org/10.5772/intechopen.69673

11. Jimenez-Garcia SN, Garcia-Mier L, Garcia-Trejo JF, Ramirez-Gomez XS, Guevara-Gonzalez RG, Feregrino-Perez AA (2018) Fusarium Mycotoxins and Metabolites that Modulate Their Production. 
Fusarium - Plant Diseases, Pathogen Diversity, Genetic Diversity, Resistance and Molecular Markers. https://doi.org/10.5772/intechopen.72874

12. Mccormick SP, Stanley AM, Stover NA, Alexander NJ (2011) Trichothecenes: From Simple to Complex Mycotoxins. Toxins 3(7):802-14

13. Da Rocha MEBD, Freire FDCO, Maia FEF, Guedes MIF, Rondina D (2014) Mycotoxins and their effects on human and animal health. Food Control 36:159-165

14. Chilaka C, Boevre MD, Atanda O, Saeger SD (2017) The Status of Fusarium Mycotoxins in SubSaharan Africa: A Review of Emerging Trends and Post-Harvest Mitigation Strategies towards Food Control. Toxins 9(1):19

15. Ortiz CS, Richards C, Terry A, Parra J, Shim W-B (2015) Genetic Variability and Geographical Distribution of Mycotoxigenic Fusarium verticillioides Strains Isolated from Maize Fields in Texas. The Plant Pathol J 31(3):203-11

16. Munkvold GP (2017) Fusarium Species and Their Associated Mycotoxins. Methods Mol Biol 1542:51-106. doi: 10.1007/978-1-4939-6707-0_4

17. Moussa TAA, Al-Zahrani HS, Kadasa NMS, Ahmed SA, Hoog GSD, Al-Hatmi AMS (2017) two new species of the Fusarium fujikuroi species complex isolated from the natural environment. Antonie van Leeuwenhoek 110(6):819-32

18. Al-Hatmi AM, Mirabolfathy M, Hagen F, Normand A-C, Stielow JB, Karami-Osbo R, et al (2016) DNA barcoding, MALDI-TOF, and AFLP data support Fusarium ficicrescens as a distinct species within the Fusarium fujikuroi species complex. Fungal Biol 120(2):265-78

19. Wu W, Chen F, Yeh K, Chen J (2018) ISSR Analysis of Genetic Diversity and Structure of Plum Varieties Cultivated in Southern China. Biology 8(1):2

20. Kozak B, Galek R, Zalewski D, Sawicka-Sienkiewicz E (2019) Preliminary Genetic Map of a New Recombinant Inbred Line Population for Narrow-leafed Lupin (Lupinusangustifolius L.). Agronomy 9(10):653

21. Rahman HU, Yue X, Yu Q, Zhang W, Zhang Q, Li P (2020) Current PCR-based methods for the detection of mycotoxigenic fungi in complex food and feed matrices. World Mycotoxin J 13(2):13950

22. Brown DW, Butchko RAE, Busman M, Proctor RH (2007) The Fusarium verticillioides FUM Gene Cluster Encodes a Zn(II)2Cys6 Protein That Affects FUM Gene Expression and Fumonisin Production. Eukaryotic Cell 6(7):1210-8

23. Seo J-A, Proctor RH, Plattner RD (2001) Characterization of Four Clustered and Coregulated Genes Associated with Fumonisin Biosynthesis in Fusarium verticillioides. Fungal Genet Biol 34(3):155-65

24. European commission (EC, 2006) Laying down the methods of sampling and analysis for the official control of the levels of mycotoxins in foodstuffs EC No. 401/2006

25. Rao VK, Girisham S, Reddy SM (2016) Prevalence of toxigenic Penicillium species associated with poultry house in Telangana, India. Archives of Env Occup Health 71(6):353-61 
26. Nayaka SC, Shankar ACU, Niranjana SR, Wulff EG, Mortensen CN, Prakash HS (2009) Detection and quantification of fumonisins from Fusarium verticillioides in maize grown in southern India. World $\mathrm{J}$ Microbiol \& Biotechnol 26(1):71-8

27. Leslie JF (2006) Summerell BA, Bullock S. The "Fusarium" laboratory manual. Ames, IA: Blackwel

28. Fusarium species: an illustrated manual for identification (1983) Pennsylvania State University Press, University Park

29. O'donnell K, Kistler HC, Cigelnik E, Ploetz RC (1998) Multiple evolutionary origins of the fungus causing Panama disease of banana: Concordant evidence from nuclear and mitochondrial gene genealogies. PNAS 95(5):2044-9

30. Sawant AM, Vankudoth R, Navale V et al. (2019) Morphological and molecular characterization of Penicillium rubens sp.nov isolated from poultry feed. Ind. Phytopathol 72, 461-478

31. Baxter B, Staden JV, Granger J, Brown N (1994) Plant-derived smoke and smoke extracts stimulate seed germination of the fire-climax grass Themedatriandra. Environ $m$ Exp Bot 34(2):217-23

32. Rao VK, Girisham S, Reddy SM (2014) Influence of different species of Penicillium and their culture filtrates on seed germination and seedling growth of sorghum. $J$ of Biochem Technol 5:832-837

33. Wollenweber HW, Reinking OA (1935) Die Fusarien, ihrebeschreibung, schadwirkung und bekmpfung. Paul Parey, Berlin

34. Nirmaladevi D, Venkataramana M, Srivastava RK, Uppalapati SR, Gupta VK, Yli-Mattila T, et al (2016) Molecular phylogeny, pathogenicity and toxigenicity of Fusarium oxysporum f. sp. lycopersici. Sci Rep 6(1) 21367

35. Girisham S, Koteswara V, Reddy, SM (2016) Taxonomy of mycotoxigenic fungi. Scientific Publishers ISBN 20:978-81-7233

36. Geiser DM, Jiménez-Gasco MDM, Kang S, Makalowska I, Veeraraghavan N, Ward TJ, et al (2004) FUSARIUM-ID v. 1.0: a DNA sequence database for identifying Fusarium. Eur J Plant Pathol 110(56):473-9

37. Thomas B, Audonneau NC, Machouart M, Debourgogne A (2019) Molecular identification of Fusarium species complexes: Which gene and which database to choose in clinical practice? J de MycolMédicale 29(1):56-8

38. Nagaraja H, Chennappa G, Rao KPC, Prasad GM, Sreenivasa MY (2016) Diversity of toxic and phytopathogenic Fusarium species occurring on cereals grown in Karnataka state, India. 3 Biotech 6(1) 57

39. Deepa N, Sreenivasa MY (2017) Fumonisins: A review on its global occurrence, epidemiology, toxicity and detection. J. of Vet Med and Resr 4: 1093

40. Borah SN, Deka S, Sarma HK (2016) First Report of Fusarium verticillioides Causing Stalk Rot of Maize in Assam, India. Plant Disease 100(7):1501

41. Ridenour JB, Smith JE, Bluhm BH (2016) The HAP Complex Governs Fumonisin Biosynthesis and Maize Kernel Pathogenesis in Fusarium verticillioides. J Food Prot 79(9):1498-507 
42. Shin J-H, Han J-H, Lee JK, Kim KS (2014) Characterization of the Maize Stalk Rot Pathogens Fusarium subglutinans and F. temperatum and the Effect of Fungicides on Their Mycelial Growth and Colony Formation. Plant Pathol J 30(4):397-406

43. Xia JW, Sandoval-Denis M, Crous PW, Zhang XG, Lombard L (2019) Numbers to namesrestyling the Fusarium incarnatum-equiseti species complex. Persoonia 43:186-221

44. González-Jartín JM, Alfonso A, Sainz MJ, Vieytes MR, Aguín O, Ferreiroa V, Botana LM (2019) First report of Fusarium foetens as a mycotoxin producer. Mycotoxin Res 35(2):177-186

45. Gullino ML, Minuto A, Gilardi G, Garibaldi A (2002) Efficacy of azoxystrobin and other strobilurins against Fusarium wilts of carnation, cyclamen and Paris daisy. Crop Prot 21, 57-61

46. Freeman S, Sharon M, Maymon M, Mendel Z, Protasov A, Aoki T, et al (2013) Fusarium euwallaceae $s p$. nov.a symbiotic fungus of Euwallacea $s p$., an invasive ambrosia beetle in Israel and California. Mycologia. 2013; 105(6):1595-606

47. Summerell BA, Leslie JF, Liew ECY, Laurence MH, Bullock S, Petrovic T, et al (2010) Fusarium species associated with plants in Australia. Fungal Diversity 46(1):1-27

48. Vieira MLC, Santini L, Diniz AL, Munhoz CDF (2016) Microsatellite markers: what they mean and why they are so useful. Genet Mol Biol 39(3):312-28

49. Chandra NS, Wulff EG, Udayashankar AC, Nandini BP, Niranjana SR, Mortensen CN, et al (2011) Prospects of molecular markers in Fusarium species diversity. App. Microbiol Biotechnol 90: 16251639

50. González-Jaén MT, Mirete S, Patiño B, López-Errasquín E, Vázquez C (2004) Genetic markers for the analysis of variability and for production of specific diagnostic sequences in fumonisin-producing strains of Fusarium verticillioides. Eur J Plant Pathol 110:525-532

51. Leyva-Madrigal KY, Larralde-Corona CP, Calderón-Vázquez CL, Maldonado-Mendoza IE (2014) Genome distribution and validation of novel microsatellite markers of Fusarium verticillioides and their transferability to other Fusarium species. J Microbiol Methods 101:18-23

52. Irzykowska L, Bocianowski J, Waśkiewicz A, Weber Z, Karolewski Z, Goliński P, et al (2012) Genetic variation of Fusarium oxysporum isolates forming fumonisin B1 and moniliformin. J Appl Genet 53(2):237-47

53. Mclean M (1995) The phytotoxicity of selected mycotoxins on mature, germinatingZea mays embryos. Mycopathol 132(3):173-83

54. Tripathi RK, Misra RS (2003) Mechanism of inhibition of maize seed germination by aflatoxin BI. In Mycotoxins in Food and Feed. 2003. Bilgrami KS, Prasad T, Sinha KK. Eds Allied Press: Bhagalpur, India, pp. 129-141

\section{Tables}




\section{Table 1}

In -vitro pathogenicity of Fusarium species on Maize

\begin{tabular}{|c|c|c|c|c|}
\hline $\begin{array}{l}\text { Isolates } \\
\text { code }\end{array}$ & $\begin{array}{l}\text { Fusarium } \\
\text { species }\end{array}$ & $\begin{array}{l}\text { Seed germination inhibition } \\
(\%)\end{array}$ & $\begin{array}{l}\text { Root inhibition } \\
(\%)\end{array}$ & $\begin{array}{l}\text { Shoot inhibition } \\
(\%)\end{array}$ \\
\hline BIONCL-1 & Fverticillioides & 40 & 8.55 & 8.24 \\
\hline BIONCL-2 & F.verticillioides & 40 & 19.81 & 28.35 \\
\hline BIONCL-4 & F.verticillioides & 30 & 19.81 & 5.67 \\
\hline BIONCL-6 & F.verticillioides & 60 & 4.05 & 19.58 \\
\hline BIONCL-7 & F.verticillioides & 10 & 16.66 & 21.13 \\
\hline BIONCL-8 & Fverticillioides & 70 & 10.81 & 8.76 \\
\hline BIONCL-9 & Fverticillioides & 20 & 11.71 & 1.28 \\
\hline BIONCL-10 & Fverticillioides & 80 & 12.16 & 7.41 \\
\hline BIONCL-11 & F.verticillioides & 30 & 9.00 & 6.28 \\
\hline BIONCL-12 & F.verticillioides & 20 & 6.75 & 7.21 \\
\hline BIONCL-14 & F.verticillioides & 20 & 40.09 & 32.98 \\
\hline BIONCL-16 & F.verticillioides & 40 & 23.42 & 21.13 \\
\hline BIONCL-17 & F.verticillioides & 70 & 47.29 & 46.39 \\
\hline BIONCL-18 & F.verticillioides & 70 & 35.58 & 20.61 \\
\hline BIONCL-19 & F.verticillioides & 90 & 25.67 & 28.35 \\
\hline BIONCL-20 & F.verticillioides & 40 & 25.67 & 28.35 \\
\hline BIONCL-22 & F.verticillioides & 60 & 7.20 & 9.02 \\
\hline BIONCL-23 & F.verticillioides & 70 & 20.04 & 21.90 \\
\hline BIONCL-24 & F.verticillioides & 90 & 2.25 & 15.46 \\
\hline BIONCL-25 & F.verticillioides & 70 & 8.10 & 1.54 \\
\hline BIONCL-26 & F.verticillioides & 90 & 2.70 & 3.09 \\
\hline BIONCL-27 & F.verticillioides & 70 & 13.96 & 17.52 \\
\hline BIONCL-28 & F.verticillioides & 60 & 4.95 & 1.54 \\
\hline BIONCL-29 & F.verticillioides & 20 & 24.77 & 21.13 \\
\hline BIONCL-30 & F.verticillioides & 70 & 22.07 & 19.58 \\
\hline BIONCL-31 & F.verticillioides & 80 & 50.90 & 30.41 \\
\hline
\end{tabular}




\begin{tabular}{|c|c|c|c|c|}
\hline BIONCL-32 & F.verticillioides & 40 & 42.34 & 35.56 \\
\hline BIONCL-33 & F.verticillioides & 00 & 20.72 & 11.81 \\
\hline BIONCL-34 & F.verticillioides & 90 & 0.00 & 21.64 \\
\hline BIONCL-35 & F.verticillioides & 80 & 21.59 & 17.11 \\
\hline BIONCL-37 & F.verticillioides & 60 & 65.31 & 56.70 \\
\hline BIONCL-38 & F.verticillioides & 80 & 30.63 & 37.62 \\
\hline BIONCL-39 & Fverticillioides & 90 & 16.66 & 38.14 \\
\hline BIONCL-40 & F.verticillioides & 50 & 67.11 & 59.79 \\
\hline BIONCL-42 & F.verticillioides & 80 & 72.07 & 62.82 \\
\hline BIONCL-43 & F.verticillioides & 90 & 32.8 & 36.08 \\
\hline BIONCL-44 & F.verticillioides & 60 & 34.23 & 32.98 \\
\hline BIONCL-45 & F.verticillioides & 40 & 43.24 & 39.17 \\
\hline BIONCL-47 & F.verticillioides & 90 & 15.76 & 28.35 \\
\hline BIONCL-48 & F.verticillioides & 20 & 25.67 & 39.17 \\
\hline BIONCL-49 & Fverticillioides & 90 & 82.43 & 71.64 \\
\hline BIONCL-50 & Fverticillioides & 90 & 12.61 & 26.80 \\
\hline BIONCL-51 & Fverticillioides & 10 & 11.10 & 27.03 \\
\hline BIONCL-52 & Fverticillioides & 70 & 8.56 & 11.10 \\
\hline BIONCL-53 & Fverticillioides & NA & NA & NA \\
\hline BIONCL-54 & Fverticillioides & 00 & 26.57 & 14.94 \\
\hline BIONCL-55 & Fverticillioides & NA & NA & NA \\
\hline BIONCL-56 & Fverticillioides & 50 & 6.78 & 28.04 \\
\hline BIONCL-57 & F.verticillioides & 30 & NA & NA \\
\hline BIONCL-58 & Fverticillioides & 60 & NA & NA \\
\hline BIONCL-59 & F.verticillioides & 70 & 7.02 & 31.07 \\
\hline BIONCL-64 & F.verticillioides & 10 & 7.20 & 18.55 \\
\hline BIONCL-71 & F.verticillioides & 80 & 4.95 & 5.67 \\
\hline BIONCL-75 & F.verticillioides & 80 & 28.37 & 38.14 \\
\hline BIONCL-60 & F. foetens & NA & 66.21 & 56.70 \\
\hline
\end{tabular}




\begin{tabular}{|lllll|} 
BIONCL-65 & F. foetens & 80 & 26.12 & 19.07 \\
\hline BIONCL-67 & F. coffeatum & 60 & 19.81 & 15.97 \\
\hline BIONCL-68 & F. coffeatum & 80 & 60.81 & 49.48 \\
\hline BIONCL-69 & F. coffeatum & 70 & 71.17 & 74.22 \\
\hline BIONCL-72 & F. coffeatum & 60 & 13.51 & 40.20 \\
BIONCL-73 & F. euwallaceae & 90 & 41.93 & 56.49 \\
\hline & Control & NA & NA & NA \\
\hline
\end{tabular}

Table 2

Diversity study for two ISSR primers with Simpson's index of diversity (SID) and Jackknife pseudovalues at confidence interval of $95 \%$ and entropy $(H)$

\begin{tabular}{|lllll|} 
ISSR primer & \# partitions & Simpson's ID & Jackknife pseudo-values Cl (95\%) & $\mathrm{H}$ \\
& 2 & 0.230 & $(0.088-0.372)$ & 0.556 \\
$(\mathrm{AG})_{8} \mathrm{C}$ & 2 & 0.283 & $(0.141-0.425)$ & 0.650 \\
& 4 & 0.663 & $(0.593-0.733)$ & 1.666 \\
& 4 & 0.760 & $(0.741-0.778)$ & 1.987 \\
& 6 & 0.762 & $(0.700-0.824)$ & 2.201 \\
& 2 & 0.073 & $(-0.027-0.172)$ & 0.229 \\
& 4 & 0.595 & $(0.489-0.702)$ & 1.492 \\
$(\mathrm{AG})_{8} \mathrm{G}$ & 3 & 0.579 & $(0.492-0.665)$ & 1.352 \\
& 5 & 0.755 & $(0.705-0.806)$ & 2.078 \\
& 7 & 0.785 & $(0.729-0.842)$ & 2.364 \\
\hline
\end{tabular}

\section{Figures}




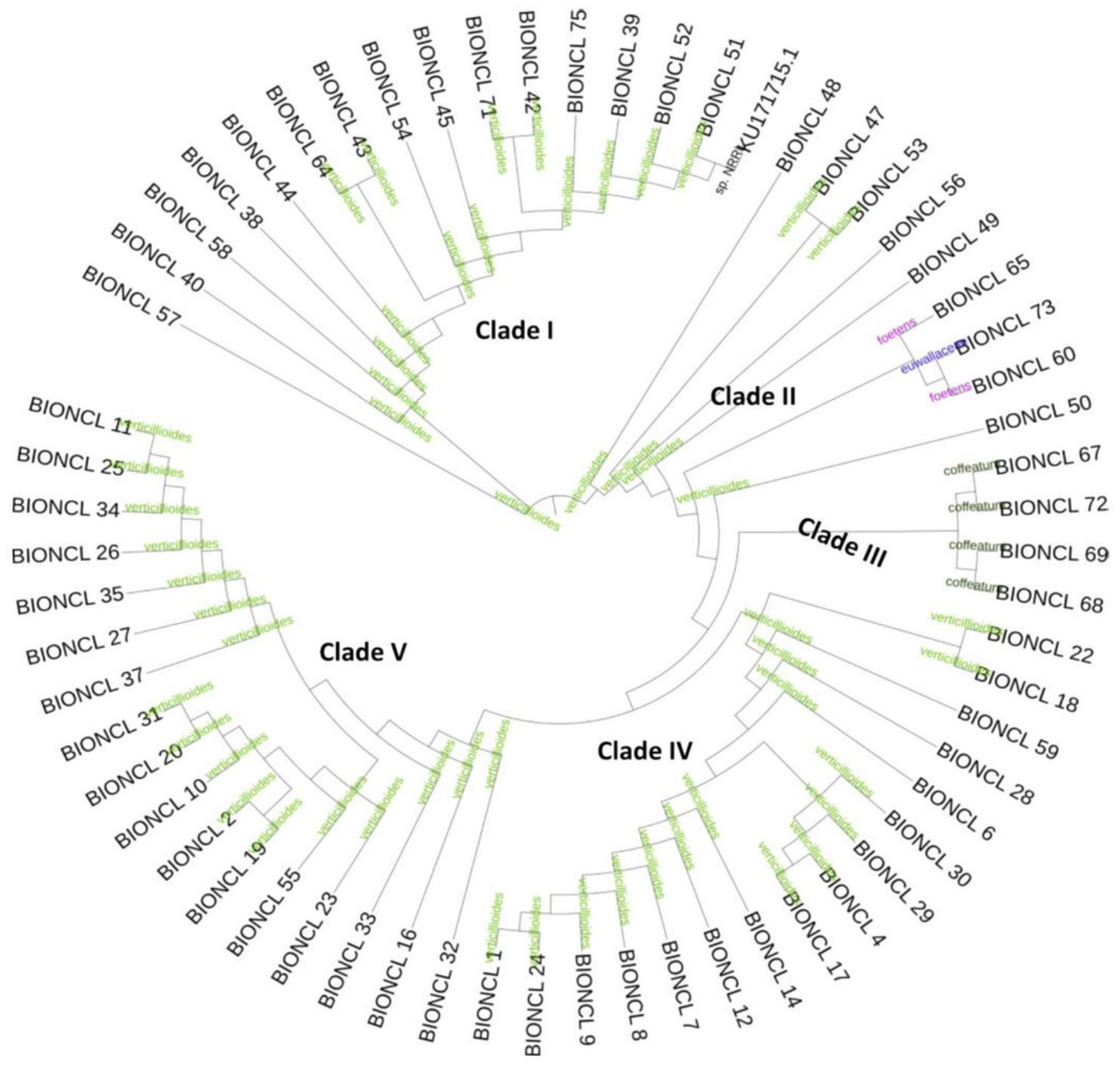

Figure 1

Phylogenetic tree analysis of Fusarium isolates based on TEF1-a sequences 


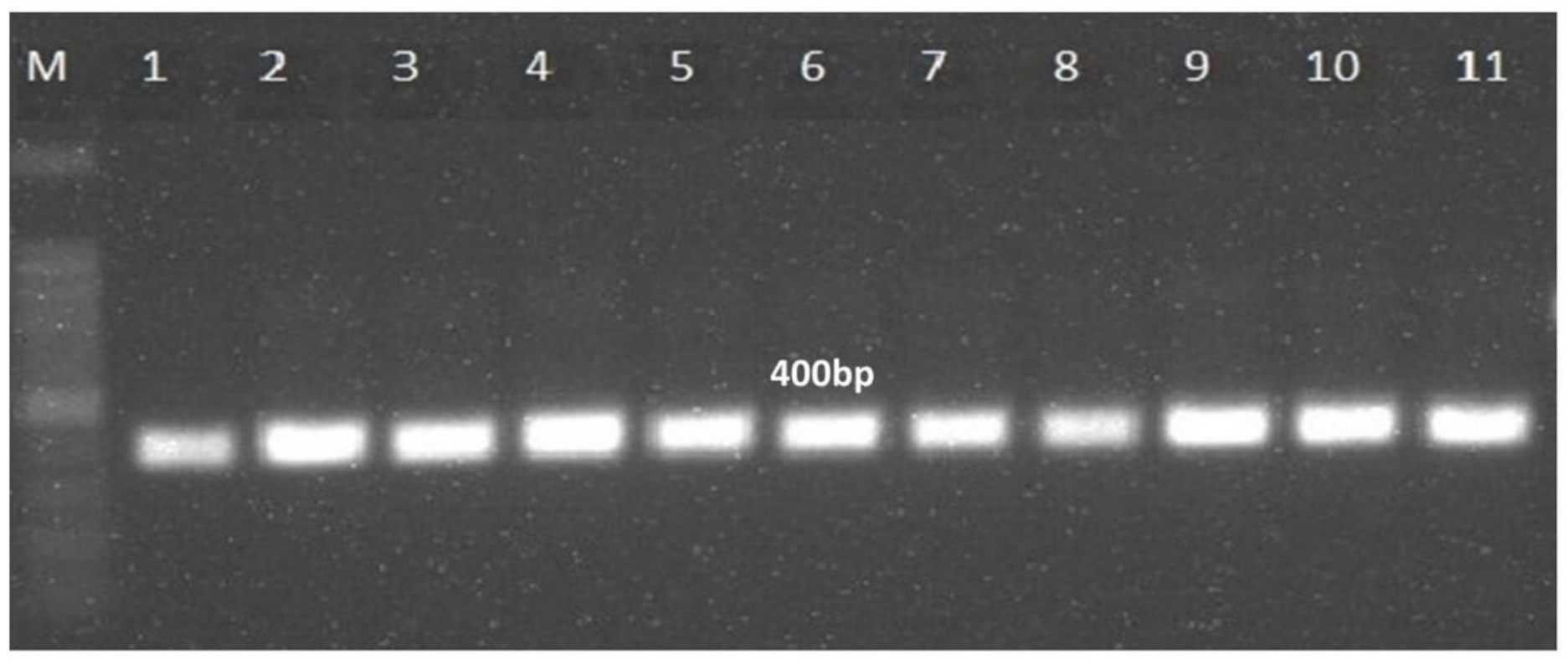

Figure 2

Fusarium verticillioides species specific PCR assay by vert f1 and vert f2 . Lane M - 100bp DNA ladder, lane 1 to 11 Fusarium verticillioides isolates
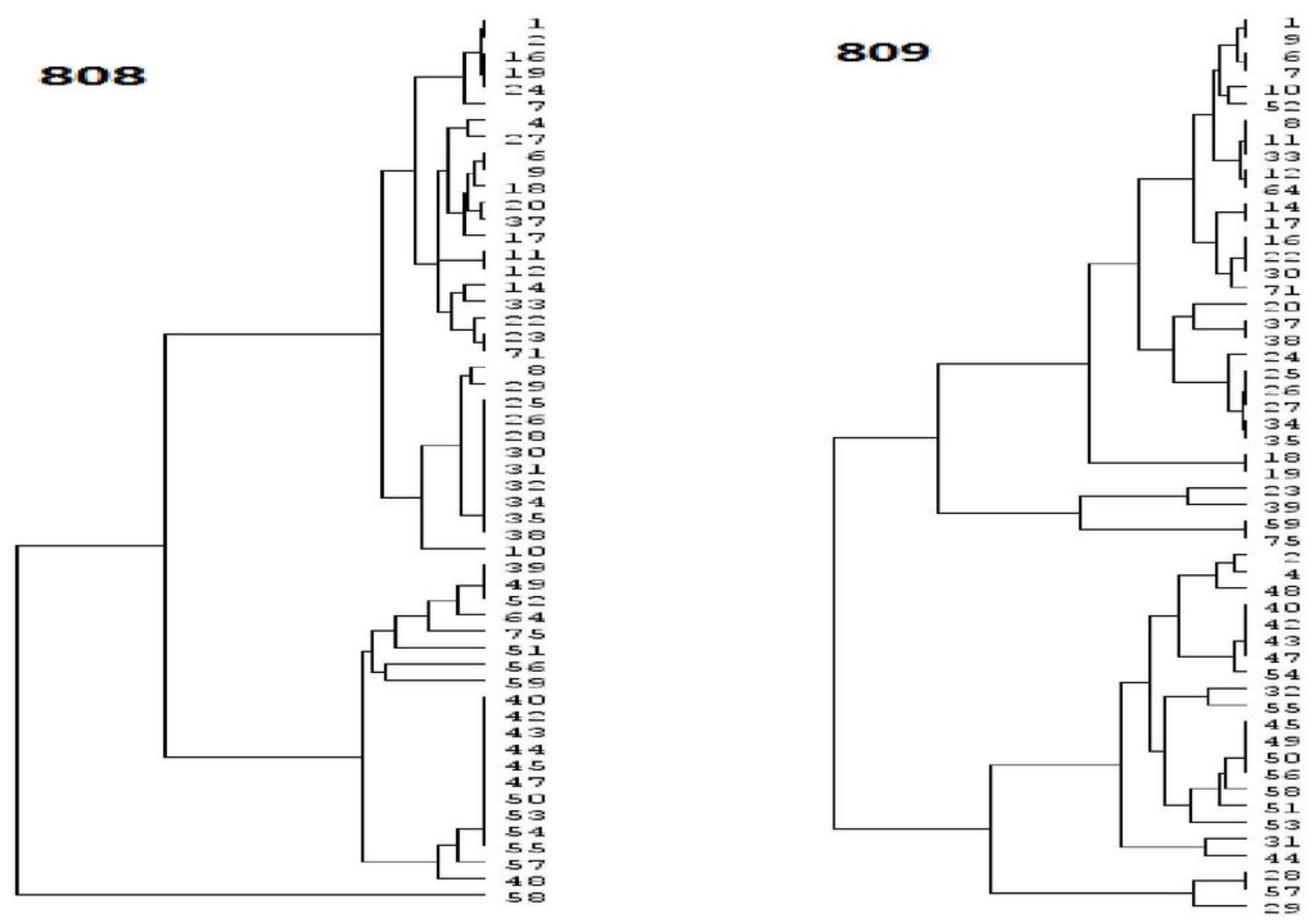
Figure 3

Phylogenetic tree of F. verticillioides strains by ISSR analysis with (AG)8C (808) primer and (AG)8G (809) primers

Cluster analysis $(\mathrm{AG})_{8} \mathrm{C}$

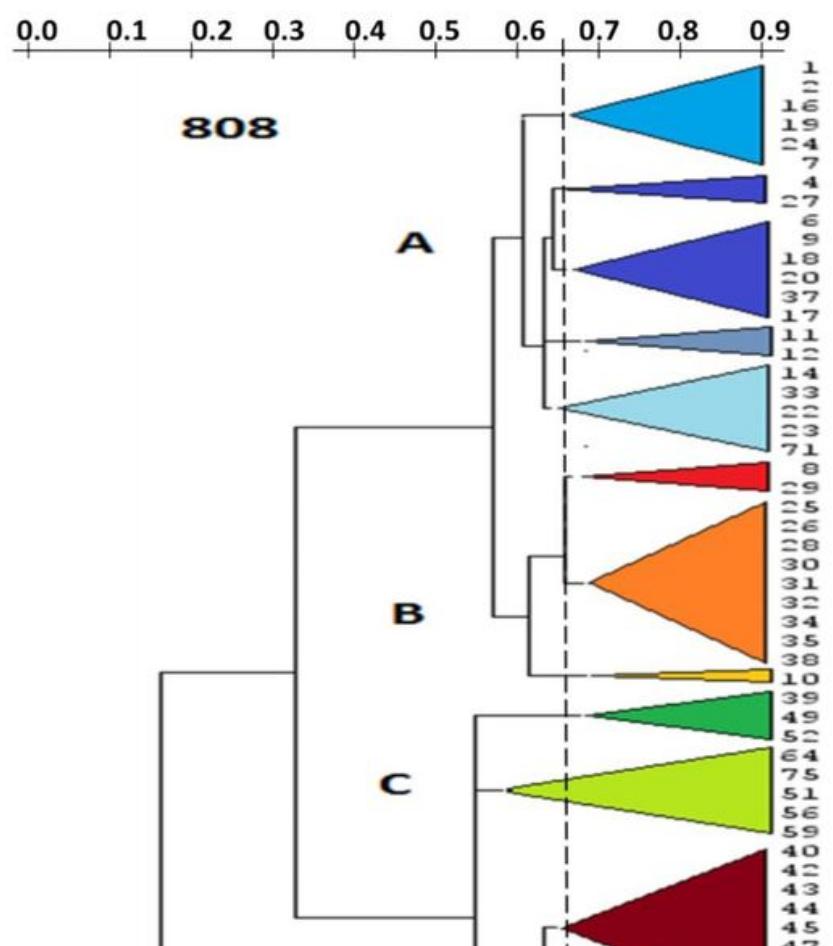

Cluster analysis $(\mathrm{AG})_{8} \mathrm{G}$

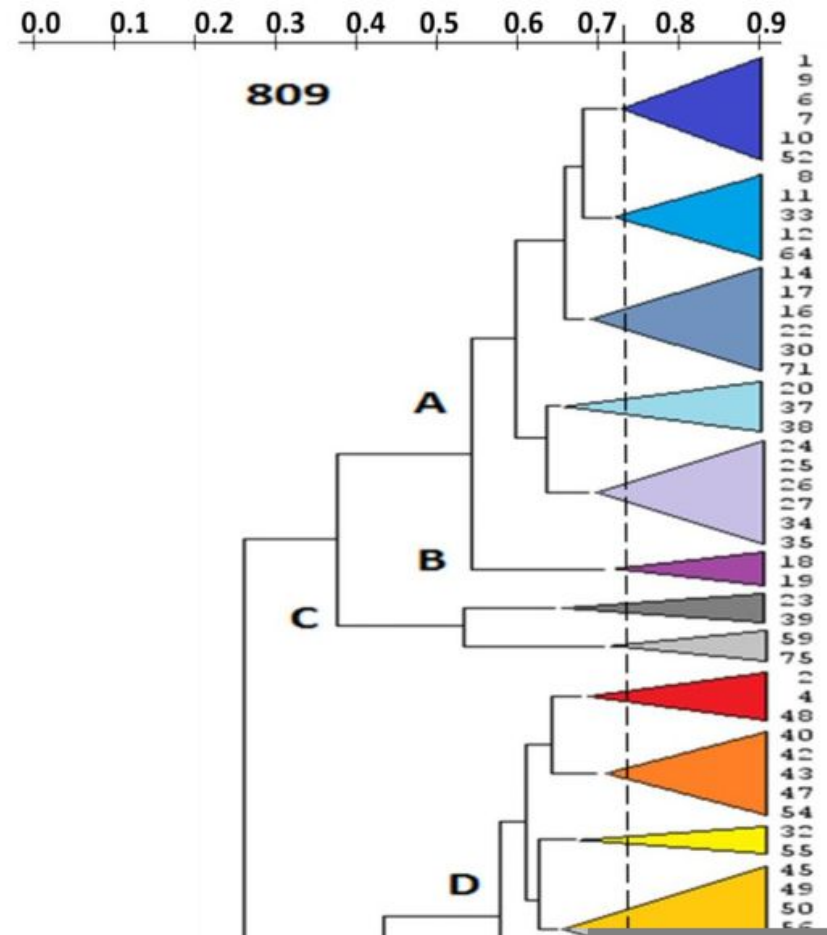

\section{Figure 4}

Cluster analysis of F. verticillioides strains by ISSR analysis (AG)8C (808) primer and (AG)8G (809) primers 


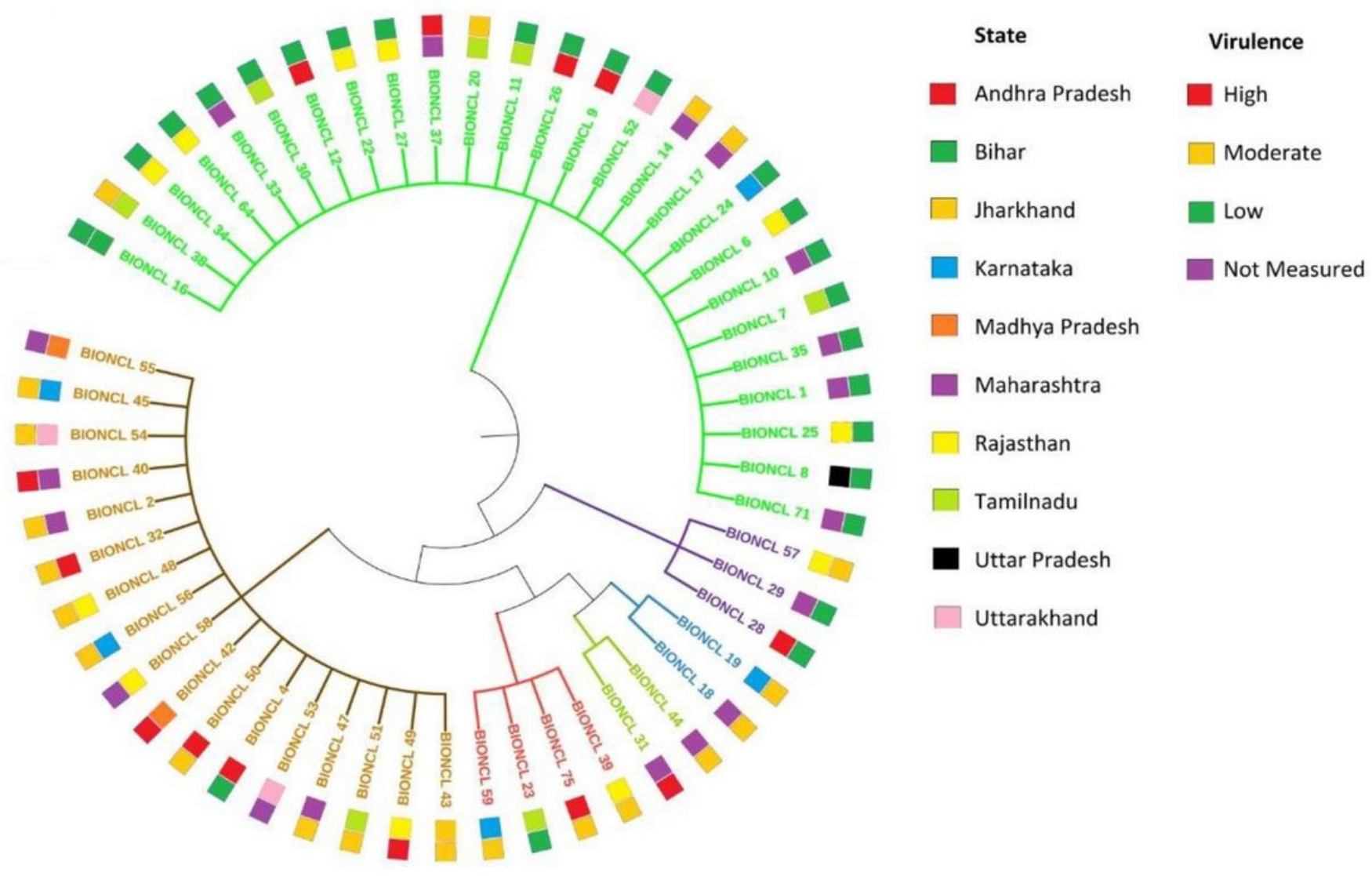

Figure 5

Phylogenetic analysis of Fusarium verticillioides strains based on (AG)8G ISSR primer and their pathogenicity distribution in maize

\section{Supplementary Files}

This is a list of supplementary files associated with this preprint. Click to download.

- MSsupplimentarydata.docx 